\title{
Nicardipine is more effective than esmolol at preventing blood pressure increases during emergence from total intravenous anesthesia
}

\author{
Department of Anesthesiology and Pain Medicine, *Seoul National University Bundang Hospital, Seongnam, \\ ${ }^{\dagger}$ Seoul National University Hospital, Seoul, Korea \\ Sang-Hyun Park*, Sang-Hwan Do*, Hye-Young Shin ${ }^{\dagger}$, Young-Tae Jeon*, \\ Jung-Won Hwang*, and Sung-Hee Han*
}

\begin{abstract}
Background: This prospective, randomized, double-blind study was undertaken to compare prophylactic nicardipine infusion with esmolol infusion to determine their effects on the control of hemodynamic response during emergence from total intravenous anesthesia (TIVA) with propofol and remifentanil.

Methods: One hundred and thirty two patients undergoing thyroidectomy were divided randomly into 3 groups. About 10 minutes before the end of surgery, propofol was stopped in all the patients and nicardipine group $(\mathrm{n}=44)$ received a continuous infusion of $2 \mu \mathrm{g} / \mathrm{kg} / \mathrm{min}$ nicardipine during emergence from TIVA, esmolol group ( $\mathrm{n}=44)$ received $250 \mu \mathrm{g} / \mathrm{kg} / \mathrm{min}$ esmolol, and placebo group received 10-14 $\mathrm{ml} / \mathrm{hr}$ of isotonic saline until $15 \mathrm{~min}$ after transfer to a postanesthesia care unit (PACU). Hemodynamic profiles were measured every minute throughout the study period.

Results: MBP was significantly lower in the nicardipine group than in the esmolol group $(\mathrm{P}<0.05)$ from 10 min after PACU transfer until $10 \mathrm{~min}$ after study drug infusion stop. On the other hand, HR was significantly lower in the esmolol group than in the nicardipine group from 6 min after drug infusion.

Conclusions: Nicardipine infusion attenuated blood pressure increases more effectively than esmolol infusion during emergence from TIVA. (Korean J Anesthesiol 2009; 57: 597 603)
\end{abstract}

Key Words: Esmolol, Intravenous infusions, Nicardipine, Total intravenous anesthesia.

\section{INTRODUCTION}

Emergence from general anesthesia and tracheal extubation is often accompanied with tachycardia and hypertension [1]. It has been reported that patients experience 37\%, 50\% and 55\% increases in systolic blood pressure (BP), diastolic BP, and heart rate (HR), respectively, during tracheal extubation [2].

Received: May 25, 2009.

Revised: 1st, June 9, 2009; 2nd, July 29, 2009.

Accepted: August 14, 2009.

Corresponding author: Sang-Hwan Do, M.D., Department of Anesthesiology and Pain Medicine, Seoul National University Bundang Hospital, Gumidong, Bundang-gu, Seongnam 463-707, Korea. Tel: 82-31-787-7501, Fax: 82-31-787-4063, E-mail: shdo@ @nu.ac.kr

Copyright (C) Korean Society of Anesthesiologists, 2009

(c) This is an open-access article distributed under the terms of the Creative Commons Attribution License, which permits unrestricted use, distribution, and reproduction in any medium, provided the original work is properly cited.
Accordingly, it is imperative that these hemodynamic responses be controlled in patients with unstable cardiovascular status to prevent complications.

Total intravenous anesthesia (TIVA) with propofol and remifentanil allows rapid and predictable titration of anesthesia, and swift consciousness and respiration recovery even after prolonged anesthesia. However, despite these potential advantages of TIVA, postoperative complications such as hypertension may be common [3]. In addition, the incidence of hypertension after TIVA has been reported to be higher than inhalation anesthesia with fentanyl [4]. Several studies have addressed the effectivenesses of esmolol or nicardipine with respect to the blunting of hemodynamic alterations associated with emergence from anesthesia [5-8].

This prospective, randomized and double-blind study was designed to compare the hemodynamic effects of nicardipine and esmolol infusions during emergence from TIVA with propofol and remifentanil. 


\section{MATERIALS AND METHODS}

After obtaining approval from the Institutional Review Board of Seoul National University Bundang Hospital and written informed consent from all study subjects, 132 adult patients aged 18-70 with American Society of Anesthesiologists physical statuses 1 or 2 were enrolled in this study. The enrollment criteria applied were scheduled total thyroidectomy under general anesthesia. Patients with a cardiovascular or pulmonary disorder, or diabetes were excluded.

The patients received $0.04 \mathrm{mg} / \mathrm{kg}$ i.v. midazolam premedication before entering the operation room. Electrocardiography, noninvasive blood pressure monitoring and pulse oximetry were established. Electrodes were placed on the forehead to monitor bispectral index (BIS) (A-2000 BIS $^{\mathrm{TM}}$ monitor, Aspect ${ }^{\mathrm{R}}$ Medical Systems, Natick, MA, USA). Preinduction mean blood pressure (MBP) and heart rate (HR) were defined as the average of three repeated measures obtained one day before surgery. Anesthesia was induced with target-controlled infusion (TCI) using an Orchestra ${ }^{\circledR}$ infusion pump system (Fresenius Kabi, Brezins, France). Patients received propofol $4 \mu \mathrm{g} / \mathrm{ml}$ and remifentanil $4 \mathrm{ng} / \mathrm{ml}$. Muscle paralysis was achieved with vecuronium $0.15 \mathrm{mg} / \mathrm{kg}$ prior to tracheal intubation. Subsequently, lungs were ventilated with oxygen and medical air $\left(\mathrm{FiO}_{2} \quad 0.5\right)$, tidal volume was adjusted to maintain an end-tidal dioxide partial pressure between 4.3 and $4.7 \mathrm{kPa}$.

Anesthesia was maintained using propofol and remifentanil. Effect-site target concentrations of propofol were adjusted to maintain BIS between 40-50 and those of remifentanil were adjusted using clinical signs and hemodynamic measurements. Inadequate anesthesia was defined as an increase in MBP or $\mathrm{HR}$ of more than $20 \%$ of the preanesthetic value. If inadequate anesthesia or hypotension (systolic BP $<85 \mathrm{mmHg}$ ) occurred when BIS was within the recommended range, the target concentration of remifentanil was increased or decreased, respectively. Preoperative infiltration of $0.75 \%$ ropivacaine was performed at the incision site. During operations, lactated Ringer's solution administration was administered at $4 \mathrm{ml} / \mathrm{kg} / \mathrm{hr}$.

Patients were randomly assigned to one of three groups: 1) $2 \mu \mathrm{g} / \mathrm{kg} / \mathrm{min}$ nicardipine (the nicardipine group) [9], 2) $250 \mu \mathrm{g} /$ $\mathrm{kg} / \mathrm{min}$ esmolol (the esmolol group) [10], or 3) $10-14 \mathrm{ml} / \mathrm{hr}$ of isotonic saline (the placebo group). Randomization was performed using computer-generated codes that were kept in sealed opaque envelopes. An anesthetic nurse unaware of treat- ment assignments prepared study drugs as $20 \mathrm{ml}$ solutions in identical black syringes labeled with infusion rate per hour of the drug according to patient weight. Nicardipine was diluted to $500 \mu \mathrm{g} / \mathrm{ml}$ and esmolol to $50 \mathrm{mg} / \mathrm{ml}$. Anesthesiologists and investigators who collected postoperative data at postanesthesia care unit (PACU) and wards were also unaware of randomization details and study drugs allocations.

Propofol infusion was stopped approximately $10 \mathrm{~min}$ before the anticipated end of surgery (skin closure). Thereafter, the study medications were continuously infused at the indicated rates until $15 \mathrm{~min}$ after PACU transfer. At the end of surgery (about 7-8 $\mathrm{min}$ after study medication infusion), remifentanil infusion was discontinued and then neuromuscular blockade was reversed with pyridostigmine $0.3 \mathrm{mg} / \mathrm{kg}$ and glycopyrrolate $0.01 \mathrm{mg} / \mathrm{kg}$. All patients' tracheas were carefully extubated when they were able to obey commands and spontaneous respiration was deemed adequate. Baseline MBP and HR were defined as the values just before study drug infusion. BIS, HR and BP were measured every minute for up to 10 minutes from study drug infusion and times to extubation were recorded. The hypotensive patients (systolic BP $<85 \mathrm{mmHg}$ or mean $\mathrm{BP}<60 \mathrm{mmHg}$ ) and patients with bradycardia (HR $<45 \mathrm{bpm}$ ) after study drug infusion were excluded from analysis. The total amounts of propofol and remifentanil infused during operations were recorded.

Five, 10 and $15 \mathrm{~min}$ after transfer to PACU, MBP and HR were recorded without pain control. Subsequently, ketorolac (30 $\mathrm{mg}$ ) was administered when patients complained of pain and a fixed dose of intermittent nicardipine $(1 \mathrm{mg}$ ) for hypertension (systolic BP $>160 \mathrm{mmHg}$ ) in all groups. Five, $10 \mathrm{~min}$ after discontinuing study medication, immediately and 6 hour after arrival in a ward, MBP and HR were recorded. Rate-pressure products (RPP) were calculated by multiplying systolic BP by HR.

Sample size was determined using our pilot study results obtained from 40 patients and were based on the assumption that a $15 \mathrm{mmHg}$ difference in MBP is clinically relevant. Power analysis suggested that a minimum of 38 patients per group would be required for a $\beta=0.1$ and $\alpha=0.05$. To compensate for potential dropouts, we enrolled 44 patients in each of the three groups. Data are presented as mean values \pm SD unless noted otherwise. The patient's age, weight, height, MBP, HR, BIS, time to extubation and total doses of propofol or remifentanil were analyzed using one-way analysis of variance, and Scheffe's method was used for multiple comparison 
Park et al : Effects of nicardipine and esmolol at emergence

Table 1. Demographic Characteristics and amounts of Anesthetics Used

\begin{tabular}{|c|c|c|c|c|}
\hline & Placebo $(\mathrm{n}=44)$ & Nicardipine $(n=43)$ & Esmolol $(n=42)$ & $P$ value \\
\hline $\operatorname{Sex}(M / F)$ & $11 / 32$ & $11 / 32$ & $8 / 34$ & 0.715 \\
\hline Age (yr) & $45 \pm 11$ & $48 \pm 11$ & $48 \pm 11$ & 0.416 \\
\hline Weight $(\mathrm{kg})$ & $61 \pm 10$ & $65 \pm 10$ & $61 \pm 9$ & 0.217 \\
\hline Height $(\mathrm{cm})$ & $161 \pm 8$ & $161 \pm 8$ & $160 \pm 7$ & 0.529 \\
\hline Total dose of propofol (mg) & $890 \pm 240$ & $861 \pm 266$ & $883 \pm 251$ & 0.878 \\
\hline Total dose of remifentanil $(\mu \mathrm{g})$ & $759 \pm 254$ & $719 \pm 219$ & $712 \pm 259$ & 0.691 \\
\hline Mean time to extubation after drug infusion (min) & $9.1 \pm 0.7$ & $9.0 \pm 0.6$ & $9.1 \pm 0.8$ & 0.85 \\
\hline
\end{tabular}

Data are mean \pm SD or numbers (n). Patients in the nicardipine and esmolol groups receive a continuous infusion of $2 \mu \mathrm{g} / \mathrm{kg} / \mathrm{min}$ nicardipine or $250 \mu \mathrm{g} / \mathrm{kg} / \mathrm{min}$ esmolol respectively during emergence from total intravenous anesthesia, while the placebo group receives $10-14 \mathrm{ml} / \mathrm{hr}$ normal saline.

Table 2. Rescue Drugs Used for Pain, Bradycardia and Hypertension

\begin{tabular}{lccc}
\hline & $\begin{array}{c}\text { Placebo } \\
(\mathrm{n}=44)\end{array}$ & $\begin{array}{c}\text { Nicardipine } \\
(\mathrm{n}=43)\end{array}$ & $\begin{array}{c}\text { Esmolol } \\
(\mathrm{n}=42)\end{array}$ \\
\hline Ketorolac 30 mg IVS & 13 & 13 & 14 \\
Atropine 0.5 mg IVS & 0 & 0 & $1^{*}$ \\
Nicardipine 1 mg IVS & 4 & 0 & 3 \\
\hline
\end{tabular}

Data are numbers of patients (n). The nicardipine and esmolol groups receive a continuous infusion of $2 \mu \mathrm{g} / \mathrm{kg} / \mathrm{min}$ nicardipine or $250 \mu \mathrm{g} / \mathrm{kg} / \mathrm{min}$ esmolol during emergence from total intravenous anesthesia, while the placebo group receives $10-14 \mathrm{ml} / \mathrm{hr}$ normal saline. *One patient suffers from bradycardia after esmolol infusion. This case is excluded from the analysis of mean blood pressure and heart rate profiles.

analysis. The Chi square test or Fisher's exact test was used to compare the noncontinuous demographic data and the numbers of patients receiving postoperative rescue treatments. Changes in MBP, HR, and BIS values over time were analyzed using repeated measures analysis of variance with multiple comparisons versus baseline values. $\mathrm{P}$ values of $<0.05$ were considered statistically significant.

\section{RESULTS}

Of the 132 enrolled patients, 3 patients were excluded from the analysis because of hypotension ( 1 in the nicardipine group and 1 in the esmolol group) and bradycardia (1 in the esmolol group). Demographic data for the remaining 129 patients are shown in Table 1. No significant differences were apparent among the esmolol, nicardipine, and placebo group with regard to demographic characteristics or anesthetic drug requirements. The number of patients administered with atropine, post-

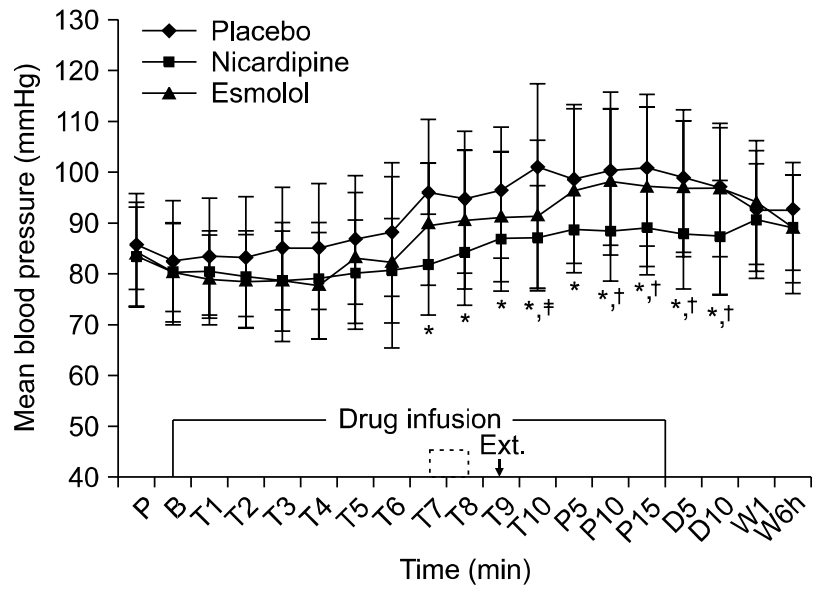

Fig. 1. Perioperative changes in mean blood pressure. The nicardipine and esmolol groups receive a continuous infusion of $2 \mu \mathrm{g} / \mathrm{kg} / \mathrm{min}$ nicardipine or $250 \mu \mathrm{g} / \mathrm{kg} / \mathrm{min}$ esmolol during emergence from total intravenous anaesthesia, while the placebo group receives $10-14$ $\mathrm{ml} / \mathrm{hr}$ of normal saline. Dotted line: at the end of surgery, remifentanil infusion is discontinued and the neuromuscular blockade is reversed. Ext: extubation, P: at ward, B: before study drug infusion, $1 \mathrm{~min}$ (T1), $2 \mathrm{~min}$ (T2), $3 \mathrm{~min}$ (T3), $4 \mathrm{~min}$ (T4), $5 \mathrm{~min}$ (T5), $6 \mathrm{~min}$ (T6), $7 \mathrm{~min}$ (T7), $8 \mathrm{~min}$ (T8), $9 \mathrm{~min}$ (T9), $10 \mathrm{~min}$ (T10) after study drug infusion, $5 \mathrm{~min}$ (P5), $10 \mathrm{~min}$ (P10), 15 min (P15) after transfer to PACU, $5 \mathrm{~min}$ (D5), $10 \mathrm{~min}$ (D10) after discontinuing study medication, immediately (W1) and 6 hours (W6h) after ward transfer. ${ }^{*} \mathrm{P}<0.05$ : MBP is significantly lower in the nicardipine group than in the placebo group. ${ }^{\dagger} \mathrm{P}<$ 0.05: MBP is significantly lower in the nicardipine group than in the esmolol group. ${ }^{\ddagger} \mathrm{P}<0.05$ : MBP is significantly lower in the esmolol group than in the placebo group.

operative ketorolac, and nicardipine (1 $\mathrm{mg})$ were also comparable in the three groups (Table 2).

Pre-induction and baseline MBP values were similar among the three groups (Fig. 1). Compared to baseline, increases in 


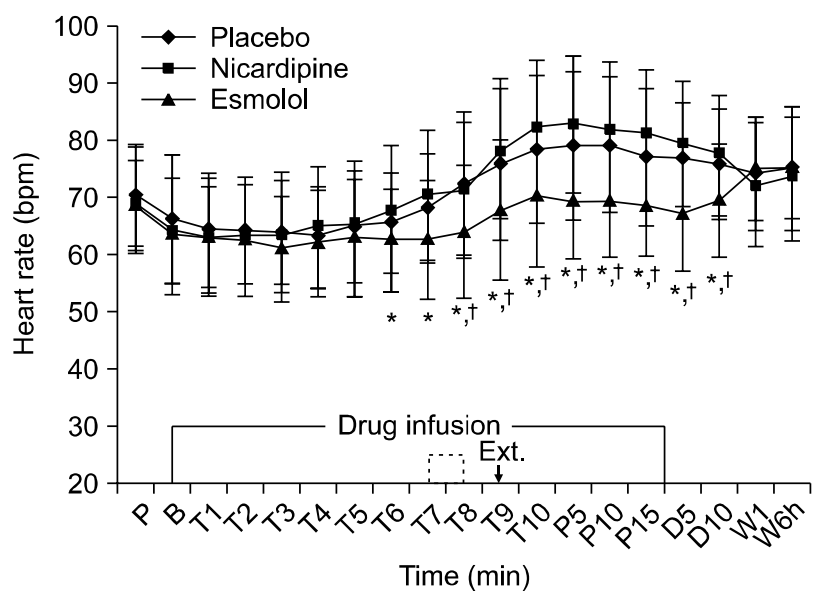

Fig. 2. Perioperative changes in heart rate. The nicardipine and esmolol groups receive a continuous infusion of $2 \mu \mathrm{g} / \mathrm{kg} / \mathrm{min}$ nicardipine or $250 \mu \mathrm{g} / \mathrm{kg} / \mathrm{min}$ esmolol during emergence from total intravenous anesthesia, while the placebo group receives $10-14$ $\mathrm{ml} / \mathrm{hr}$ normal saline. Dotted line: at the end of surgery, remifentanil infusion is discontinued and the neuromuscular blockade is reversed. Ext: extubation, P: at ward, B: before study drug infusion, $1 \mathrm{~min}$ (T1), $2 \mathrm{~min}$ (T2), $3 \mathrm{~min}$ (T3), $4 \mathrm{~min}$ (T4), $5 \mathrm{~min}$ (T5), $6 \mathrm{~min}$ (T6), $7 \min (\mathrm{T} 7), 8 \min$ (T8), $9 \min$ (T9), $10 \min$ (T10) after study drug infusion, $5 \mathrm{~min}$ (P5), $10 \mathrm{~min}$ (P10), $15 \mathrm{~min}$ (P15) after transfer to PACU, 5 min (D5), $10 \mathrm{~min}$ (D10) after discontinuing study medication, immediately (W1) and 6 hours (W6h) after ward transfer. ${ }^{*} \mathrm{P}<0.05$ : HR is significantly lower in the esmolol group than in the nicardipine group. ${ }^{\dagger} \mathrm{P}<0.05$ : $\mathrm{HR}$ is significantly lower in the esmolol group than in the placebo group.

MBP were observed from $10 \mathrm{~min}$ after infusion start in nicardipine group, $7 \mathrm{~min}$ in esmolol and in placebo group. From $10 \mathrm{~min}$ after transfer to PACU until $10 \mathrm{~min}$ after infusion stop, MBP was significantly lower in the nicardipine group than in the esmolol group $(\mathrm{P}<0.05)$.

Pre-induction and baseline HR values were comparable among the three groups (Fig. 2). Compared to baseline, increases in HR were observed from $10 \mathrm{~min}$ after infusion start in esmolol group, $7 \mathrm{~min}$ in nicardipine and in placebo group. HR was significantly lower in the esmolol group than in the nicardipine group from $6 \mathrm{~min}$ after drug infusion. No differences in HR were observed between the nicardipine and placebo group at any time.

RPP was significantly lower in the esmolol group than in the placebo group from $8 \mathrm{~min}$ after drug infusion (Fig. 3), but the esmolol and nicardipine groups were comparable. BIS values were similar at each time point among the three groups (Fig. 4).

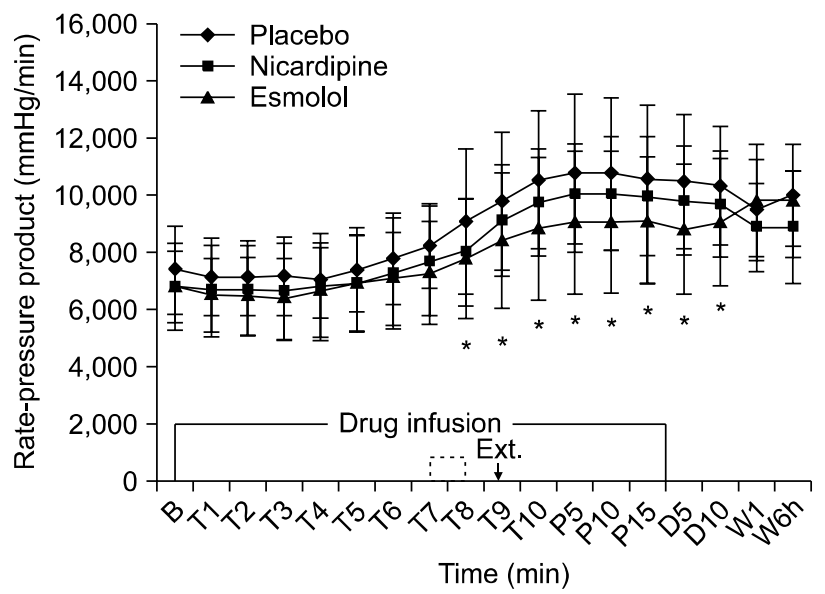

Fig. 3. Perioperative changes in rate-pressure product. The nicardipine and esmolol groups receive a continuous infusion of $2 \mu \mathrm{g} / \mathrm{kg} / \mathrm{min}$ nicardipine or $250 \mu \mathrm{g} / \mathrm{kg} / \mathrm{min}$ esmolol during emergence from total intravenous anesthesia, while the placebo group receives $10-14$ $\mathrm{ml} / \mathrm{hr}$ of normal saline. Dotted line: at the end of surgery, remifentanil infusion is discontinued and the neuromuscular blockade is reversed. Ext: extubation, B: before study drug infusion start, 1 $\min$ (T1), $2 \min (\mathrm{T} 2), 3 \min (\mathrm{T} 3), 4 \min (\mathrm{T} 4), 5 \min (\mathrm{T} 5), 6$ $\min$ (T6), $7 \min (\mathrm{T} 7), 8 \min (\mathrm{T} 8), 9 \min (\mathrm{T} 9), 10 \min (\mathrm{T} 10)$ after study drug infusion, $5 \mathrm{~min}$ (P5), $10 \mathrm{~min}$ (P10), $15 \mathrm{~min}$ (P15) after transfer to PACU, $5 \mathrm{~min}$ (D5), $10 \mathrm{~min}$ (D10) after discontinuing study medication, immediately (W1) and 6 hours (W6h) after ward transfer. ${ }^{*} \mathrm{P}<0.05$ : RPP is significantly lower in the esmolol group than in the placebo group. Rate-pressure product $=$ systolic BP $\times$ HR.

\section{DISCUSSION}

Clinical studies have demonstrated that emergence from TIVA with propofol and remifentanil as compared with balanced anesthesia using inhalation anesthetics and opioid, is accompanied by an increased incidence of hypertension requiring antihypertensive medication to maintain MBP within 20\% of baseline [4,11]. Moreover, a higher incidence of hypertension after remifentanil-based anesthesia has been previously described and was attributed to inadequate analgesia after stopping remifentanil infusion [12]. Therefore, anesthesiologists using TIVA should consider employing antihypertensive therapy more liberally at around the end of surgical procedures.

The recommended infusion rate of esmolol is reported to be $200-300 \mu \mathrm{g} / \mathrm{kg} / \mathrm{min}[10,13]$ and that of nicardipine to be $1-$ $3 \mu \mathrm{g} / \mathrm{kg} / \mathrm{min}$ [9,14]. Thus, we chose median values of these ranges as infusion rates for this study (esmolol $250 \mu \mathrm{g} / \mathrm{kg} / \mathrm{min}$, nicardipine $2 \mu \mathrm{g} / \mathrm{kg} / \mathrm{min}$ ). A small loading dose (e.g., esmlolol 
Park et al : Effects of nicardipine and esmolol at emergence

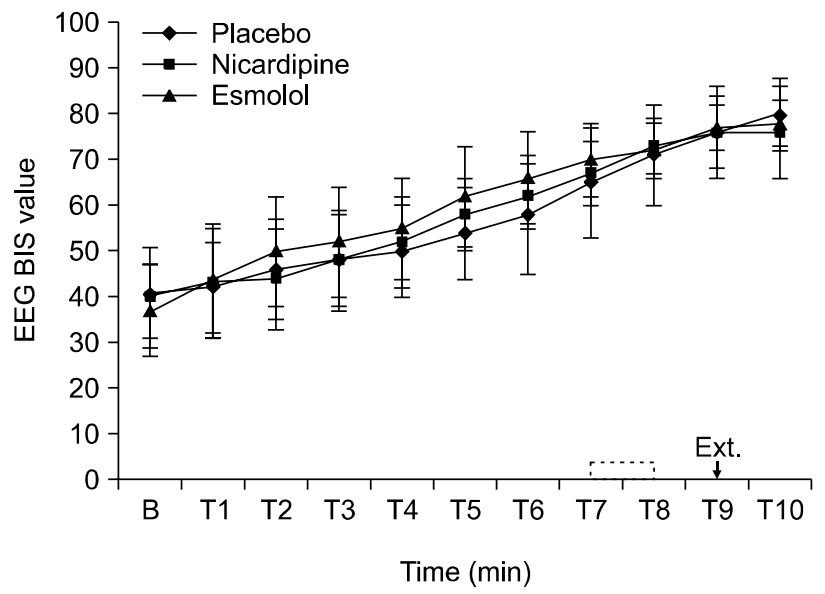

Fig. 4. Perioperative changes in electroencephalographic (EEG) bispectral index (BIS) in the three groups from baseline (mean \pm $\mathrm{SD})$. The nicardipine and esmolol groups receive a continuous infusion of $2 \mu \mathrm{g} / \mathrm{kg} / \mathrm{min}$ nicardipine or $250 \mu \mathrm{g} / \mathrm{kg} / \mathrm{min}$ esmolol during emergence from total intravenous anesthesia, while the placebo group receives $10-14 \mathrm{ml} / \mathrm{hr}$ normal saline. Dotted line: at the end of surgery, remifentanil infusion is discontinued and the neuromuscular blockade is reversed. No differences are evident among the three groups. Ext: extubation, B: before study drug infusion start, $1 \min (\mathrm{T} 1), 2 \min (\mathrm{T} 2), 3 \min (\mathrm{T} 3), 4 \min (\mathrm{T} 4), 5 \mathrm{~min}$ (T5), $6 \min$ (T6), $7 \min$ (T7), $8 \min$ (T8), $9 \min$ (T9), $10 \mathrm{~min}$ (T10) after study drug infusion.

$500 \mu \mathrm{g} / \mathrm{kg} / \mathrm{min}$ or nicardipine $5 \mu \mathrm{g} / \mathrm{kg} / \mathrm{min}$ ) has been used in most investigations involving endotracheal intubation or controlled hypotension. However, this loading dose was omitted in the present study because it has been associated with symptomatic hypotension [15] and the purpose of this study was to prevent hypertension, not to induce hypotension.

In the esmolol group, the hypotensive effect of esmolol was not obvious. Compared with the placebo group, MBP was significantly lower at just one time point (10 min after drug infusion, Fig. 1). In addition, 3 patients in the esmolol group required bolus doses of nicardipine due to uncontrolled hypertension despite esmolol infusion in the PACU. These findings are contrary to previous investigations $[6,16]$ in which an esmolol bolus or infusion attenuated HR and BP increases after tracheal extubation. The mechanism underlying these different hemodynamic responses to esmolol appear to be associated with different cardiovascular statuses, patient characteristics (e.g., young vs. old), or different modes of anesthesia (TIVA vs. inhalation anesthesia). During TIVA, propofol causes peripheral vasodilatation [17] and after its discontinuation, there might be a rebound increase in systemic vascular resistance. In addition, esmolol is associated with a profound decrease in cardiac output and reflex increase in systemic vascular resistance [18]. Taken together, the above suggests that esmolol may be ineffective at attenuating BP increases during emergence from TIVA.

In this study, MBP was significantly lower in the nicardipine group than in the other two groups until $10 \mathrm{~min}$ after terminating drug infusion, and it was restored in the ward. This finding is consistent with a previous investigation in which time to baseline BP restoration after nicardipine infusion was approximately $20 \mathrm{~min}$ [19]. In addition, the use of nicardipine infusion requires caution when administration is prolonged (about $270 \pm 20 \mathrm{~min}$ ) because nicardipine may have a cumulative effect, which may cause resistance to vasopressors [20]. In the present study, the duration of nicardipine administration was $25 \mathrm{~min}$, which is not associated with accumulation.

No differences in HR were observed between the nicardipine and the placebo group at any time point in this study. Diverse results have been reported regarding the effect of nicardipine on HR. A nicardipine bolus is known to cause tachycardia at emergence and tracheal extubation, because of a reduced systemic vascular resistance and reflex tachycardia [7,8]. However, other investigators reported that bolus nicardipine administered to anesthetized patients did not increase HR [21], which may have been due to an attenuation of reflex sympathetic activity. In addition, it has been reported that no change in HR occurred during long-term hypotensive anesthesia with nicardipine infusion [20]. The reasons for these different hemodynamic responses to nicardipine seem to be associated with different modes of dosing (i.e., single bolus vs. continuous infusion without a loading dose) and/or different modes of anesthesia (inhalational anesthesia vs. TIVA).

Myocardial oxygen consumption $\left(\mathrm{MVO}_{2}\right)$ was not measured in this study, but RPP is a good correlate of overall $\mathrm{MVO}_{2}$ [22]. In patients with myocardial ischemia, esmolol was found to effectively reduce HR and BP, and thereby decrease RPP [23]. In our study, RPP was significantly lower in the esmolol group than in the placebo group from $8 \mathrm{~min}$ after drug infusion, but was comparable between esmolol and nicardipine group. In addition, it has been reported that the greater selectivity of nicardipine for the coronary vasculature can increase myocardial oxygen supply [24]. Therefore, nicardipine can be administered safely without the risk of RPP increase in patients with ischemic heart disease to control BP. Nicardipine can also induce favorable cerebrovascular changes in stroke 
patients. These include cerebral vasospasm reversal, cerebral blood flow augmentation, and thus oxygen delivery, and the inhibition of platelet aggregation [24]. Therefore, it makes sense to administer nicardipine before emergence from TIVA to reduce the cerebrovascular risk in patients with cerebrovascular disease.

At the end of surgery, intravenous patient-controlled analgesia (PCA) infusion was not applied in this study, because post-thyroidectomy pain is considered to be relatively mild. Moreover, skin infiltration with local anesthetic such as ropivacaine, as administered in this study, should decrease postoperative pain [25]. Although intraoperative esmolol is associated with decreased requirements in postoperative opioids [26], no significant difference was observed among the three groups with respect to rescue analgesic requirements. In addition, we were set on preserving the double-blind design of this study. The difficulties associated with blinding investigators with respect to esmolol infusion has been previously described [27], as it was expected that a decrease in HR in response to an esmolol loading dose would readily identify patients on esmolol.

In conclusion, the present study demonstrates that esmolol infusion $(250 \mu \mathrm{g} / \mathrm{kg} / \mathrm{min})$ during emergence from TIVA attenuated HR increase but only marginally affected BP increases, whereas nicardipine infusion $(2 \mu \mathrm{g} / \mathrm{kg} / \mathrm{min})$ mainly attenuated BP increase but did not affect HR or RPP. Accordingly, nicardipine infusion was found to be more effective than esmolol infusion at attenuating $\mathrm{BP}$ increases during emergence from TIVA with propofol and remifentanil.

\section{REFERENCES}

1. Hartley M, Vaughan RS. Problems associated with tracheal extubation. Br J Anaesth 1993; 71: 561-8.

2. Nishina K, Mikawa K, Takao Y, Shiga M, Maekawa N, Obara H. Prostaglandin E1, lidocaine, and prostaglandin E1-lidocaine combination for attenuating cardiovascular responses to extubation. Can J Anaesth 1997; 44: 1211-4.

3. Wong AY, O'Regan AM, Irwin MG. Total intravenous anaesthesia with propofol and remifentanil for elective neurosurgical procedures: an audit of early postoperative complications. Eur $\mathrm{J}$ Anaesthesiol 2006; 23: 586-90

4. Magni G, Baisi F, La Rosa I, Imperiale C, Fabbrini V, Pennacchiotti ML, et al. No difference in emergence time and early cognitive function between sevoflurane-fentanyl and propofol-remifentanil in patients undergoing craniotomy for supratentorial intracranial surgery. J Neurosurg Anesthesiol 2005; 17: 134-8.
5. Fuhrman TM, Ewell CL, Pippin WD, Weaver JM. Comparison of the efficacy of esmolol and alfentanil to attenuate the hemodynamic responses to emergence and extubation. J Clin Anesth 1992; 4: 444-7.

6. Dyson A, Isaac PA, Pennant JH, Giesecke AH, Lipton JM. Esmolol attenuates cardiovascular responses to extubation. Anesth Analg 1990; 71: 675-8.

7. Kovac AL, McKinley C, Tebbe CJ, Williams C. Comparison of nicardipine versus placebo to control hemodynamic responses during emergence and extubation. J Cardiothorac Vasc Anesth 2001; 15: 704-9.

8. Kovac AL, Masiongale A. Comparison of nicardipine versus esmolol in attenuating the hemodynamic responses to anesthesia emergence and extubation. J Cardiothorac Vasc Anesth 2007; 21: 45-50.

9. Tobias JD. Nicardipine: applications in anesthesia practice. J Clin Anesth 1995; 7: 525-33.

10. Figueredo E, Garcia-Fuentes EM. Assessment of the efficacy of esmolol on the haemodynamic changes induced by laryngoscopy and tracheal intubation: a meta-analysis. Acta Anaesthesiol Scand 2001; 45: 1011-22.

11. Bilotta F, Caramia R, Paoloni FP, Favaro R, Araimo F, Pinto G, et al. Early postoperative cognitive recovery after remifentanilpropofol or sufentanil-propofol anaesthesia for supratentorial craniotomy: a randomized trial. Eur J Anaesthesiol 2007; 24: 122-7.

12. Gerhardt MA, Grichnik KP. Early extubation and neurologic examination following combined carotid endarterectomy and coronary artery bypass grafting using remifentanil. J Clin Anesth 1998; 10: $249-52$

13. Korpinen R, Simola M, Saarnivaara L. Effect of esmolol on the heart rate, arterial pressure and electrocardiographic changes during laryngomicroscopy. Acta Anaesthesiol Scand 1997; 41: 371-5.

14. Bernard JM, Pinaud M, Francois T, Babin M, Macquin-Mavier I, Letenneur J. Deliberate hypotension with nicardipine or nitroprusside during total hip arthroplasty. Anesth Analg 1991; 73: 341-5.

15. Ko WJ, Chu SH. A new dosing regimen for esmolol to treat supraventricular tachyarrhythmia in Chinese patients. J Am Coll Cardiol 1994; 23: 302-6.

16. O'Dwyer JP, Yorukoglu D, Harris MN. The use of esmolol to attenuate the haemodynamic response when extubating patients following cardiac surgery--a double-blind controlled study. Eur Heart J 1993; 14: 701-4.

17. Grounds RM, Twigley AJ, Carli F, Whitwam JG, Morgan M. The haemodynamic effects of intravenous induction. Comparison of the effects of thiopentone and propofol. Anaesthesia 1985; 40: 735-40.

18. Ornstein E, Young WL, Ostapkovich N, Matteo RS, Diaz J. Deliberate hypotension in patients with intracranial arteriovenous malformations: esmolol compared with isoflurane and sodium nitroprusside. Anesth Analg 1991; 72: 639-44.

19. Hersey SL, O'Dell NE, Lowe S, Rasmussen G, Tobias JD, Deshpande JK, et al. Nicardipine versus nitroprusside for controlled hypotension during spinal surgery in adolescents. Anesth Analg 1997; 84: 1239-44. 
20. Bernard JM, Passuti N, Pinaud M. Long-term hypotensive technique with nicardipine and nitroprusside during isoflurane anesthesia for spinal surgery. Anesth Analg 1992; 75: 179-85.

21. Cheung AT, Guvakov DV, Weiss SJ, Savino JS, Salgo IS, Meng QC. Nicardipine intravenous bolus dosing for acutely decreasing arterial blood pressure during general anesthesia for cardiac operations: pharmacokinetics, pharmacodynamics, and associated effects on left ventricular function. Anesth Analg 1999; 89: 1116-23.

22. Gobel FL, Norstrom LA, Nelson RR, Jorgensen CR, Wang Y. The rate-pressure product as an index of myocardial oxygen consumption during exercise in patients with angina pectoris. Circulation 1978; 57: 549-56.

23. Sung RJ, Blanski L, Kirshenbaum J, MacCosbe P, Turlapaty P, Laddu AR. Clinical experience with esmolol, a short-acting beta-adrenergic blocker in cardiac arrhythmias and myocardial ischemia. J Clin Pharmacol 1986; 26(Suppl A): A15-26.

24. Kaplan JA. Clinical considerations for the use of intravenous nicardipine in the treatment of postoperative hypertension. Am Heart J 1990; 119: 443-6.

25. Karamanlioglu B, Turan A, Memis D, Kaya G, Ozata S, Ture M. Infiltration with ropivacaine plus lornoxicam reduces postoperative pain and opioid consumption. Can J Anaesth 2005; 52: 1047-53.

26. White PF, Wang B, Tang J, Wender RH, Naruse R, Sloninsky A. The effect of intraoperative use of esmolol and nicardipine on recovery after ambulatory surgery. Anesth Analg 2003; 97: 1633-8.

27. Raby KE, Brull SJ, Timimi F, Akhtar S, Rosenbaum S, Naimi C, et al. The effect of heart rate control on myocardial ischemia among high-risk patients after vascular surgery. Anesth Analg 1999; 88: 477-82. 